International Journal of Linguistics, Literature and Translation

ISSN: 2617-0299 (Online); ISSN: 2708-0099 (Print)

DOI: $10.32996 /$ ijllt

Journal Homepage: www.al-kindipublisher.com/index.php/ijltt

IJLLT

\title{
Metaphors' Effect on Off-line Cognition: A Preliminary Study Based on a Reaction Time Task
}

\author{
Fatemeh Shafiei ${ }^{1} \square$ and Habibollah Ghassemzadeh ${ }^{2}$ \\ ${ }^{1}$ Ph.D. Cognitive linguistics, Institute for Cognitive Sciences Studies, Tehran, Iran \\ ${ }^{2}$ Professor, Ph.D. Developmental Psychology, Department of Psychiatry. Tehran University of Medical Sciences, Tehran, Iran
}

$\square$ Corresponding Author: Fatemeh Shafiei, E-mail: s.shafiee@alumni.ut.ac.ir

\section{ARTICLE INFORMATION ABSTRACT}

Received: 14 October 2021

Accepted: 22 November 2021

Published: 30 November 2021

DOI: 10.32996/ijllt.2021.4.11.15

\section{KEYWORDS}

Structural conceptual metaphor, recognition, reaction time, schema, off-line cognition
The modality of apprehension and processing of metaphorical expressions in comparison with non-metaphorical ones has hitherto captivated numerous researchers in manifold fields of study, such as linguistics, psychology, and cognitive sciences. More specially, metaphors used in a one-sentence paragraph have been the subject of many studies. However, cognitive functions of structural metaphors haven't been entirely noteworthy in contrast with non-metaphorical expressions employed in textual context. In this study, the interrelationship between memory and conceptual metaphor in significant cognitive processes has been examined in a textual context. In this respect, the hypothesis, that conceptual metaphor as a value can assist with the recognition and recollection process and incorporate the quintessence of our cerebrations has been put to the test. To evaluate this assumption, the reaction time task is used. Each testable case has been subjected to analysis within two analogous contexts, in a metaphorical and non-metaphorical manner. Afterward, terms were displayed, and the subjects needed to determine as swiftly as possible whether these vocabularies were exemplified or not. The results indicated that the terms pertaining to the schema and other terms included in metaphorical context would be processed faster than the ones with non-metaphorical context. With regard to the obtained data, it seems that the conceptual metaphor generates semantic networks in the mind which will be more accessible to memory upon information retrieval.

\section{Introduction}

Time is an indispensable dimension of any physical, social or mental event. Time is indispensable for any event or things to be done by individuals. In scientific research, measuring time has always been a basic part. The examination of a human mind and its actions is one of the fields where time is tested. Even decades ago, psychological experiments were divided into two general categories: the test of speed and the test of power. In applying the test of speed, the reaction time is mostly highlighted. In fact, the study of reaction time refers to any empirical study, in which the time spent by a subject in responding to a stimulus or in performing a special activity is measured and analyzed. This helps to find answers to some research questions. By reaction time we mean the time, it takes for the perception of a stimulus and the possible response to it. Using reaction time is an efficient method to observe the existing relationships among physical and mental events, and also cognitive processes (Posner, 1978; Welford, 1980). Many factors can influence the time at which individuals will respond to different stimuli including the difficulty level of the stimulus, its likelihood, and familiarity as the most important factors. The more intricate the stimulus is, the more information is needed to process it and consequently, the processing procedure will take longer. Conversely, the simpler and more accessible the stimulus is, it will require little information to be processed, and the less data there is, the faster the reaction time will be.

Conceptual metaphors are one of the functions of the mind that some of its processing aspects can be measured using the reaction time task. From a cognitive perspective, Lakoff and Johnson (1980) consider metaphor as a cognitive phenomenon and they believe that metaphors are conceptual in nature. They suggest that metaphors are present outside of language in our daily life, not only

Copyright: (c) 2021 the Author(s). This article is an open access article distributed under the terms and conditions of the Creative Commons Attribution (CC-BY) 4.0 license (https://creativecommons.org/licenses/by/4.0/). Published by Al-Kindi Centre for Research and Development, London, United Kingdom. 
in our language but also in the way we think and act; and our usual conceptual system in which we think and act is fundamentally metaphorical in nature. Regarding the theoretical foundations that have been proposed on metaphor over the past few decades, it seems that metaphor has a very important role in memory and memorization processes. Metaphor comprehension involves forming an abstract connection between two concepts in semantic memory (Glucksberg, 2001, 2003). Such a link or attributive category is established by extracting and relating similar properties of different concepts in memory (Benedek, et al., 2014). In the present study, we intend to evaluate the effect of conceptual metaphors on off-line cognition, or in other words, memory, by evaluating the reaction time task.

\section{Review of literature}

The reaction time task is one of the prevalent evaluations in the disciplines of psychology, cognitive psychology, and cognitive science. This task is used extensively in the framework of information processing and is considered as one of the most basic measures in the study of perception, attention, and memory (Posner, 1978; Welford, 1980). In addition, many years ago, the reaction time task was utilized in processes that take place in the comprehension and processing of metaphors. In a straightforward classification, these tasks may be divided into two main categories. Some of them deal with the impact of conceptual metaphors in understanding some abstract concepts. The studies of Meier and his colleagues $(2004,2005,2007)$ belong to this category. For instance, in several studies, they examined the influence of the conceptual metaphor "GOOD IS UP" on understanding some abstract concepts related to ethical matters/issues by adopting reaction time tasks. They proved that when moral concepts are presented to subjects in the upper (as opposed to lower) vertical position, the subjects will decode and recognize these concepts at a faster rate rather than the time they are presented in the lower position (Meier et al., 2007). The other category of research is the studies that deal with the comparisons of the metaphorical perception of concepts with that of non-metaphorical concepts equivalent to them. The research conducted in these domains is mostly categorized in one of these two approaches, direct or indirect access. Direct access implies that metaphorical processing takes place without any further literal processing, while in indirect access, the metaphor processing goes through literal understanding first, making it an indirect process. For example, according to the paradigm of standard pragmatics by Grice (1991) and Searl (1979), the metaphors have an uncommon condition, and the mechanism of figurative language is different from the literal one. Also, the process of literal meaning transpires before the metaphorical process. In Ortony et al. (1978), the precedence of the literal process procedure in contrast to a metaphorical process has been investigated. In this study, the exact amount of time necessary for the perception of a metaphorical sentence within the contexts of both literal and metaphorical was estimated. The results demonstrated that there was no significant difference between the comprehension of metaphorical and non-metaphorical sentences. In another study performed by Inhoff and colleagues (1984), the amount of time required for reading metaphorical and non-metaphorical sentences by subjects through the eye-tracking technique was calculated as well. Results revealed that subjects read metaphorical sentences at the same speed as reading nonmetaphorical ones. Moreover, Blasko \& Connine (1993) dealt with the issue of time processing of metaphorical and literal meaning through the semantic initiation system phenomenon (Ghassemzadeh 1398: 53-57). It is vital to mention that these studies which aimed at experimenting with metaphors have mostly concentrated on the prompt judgment of the subjects on the stimuli which were available at that moment. They have focused less on how they act and refer to their memory when the stimulus is not accessible. Those few studies, which deal with conceptual metaphors in memory, are largely about orientational metaphors. In fact, it can be said that the only empirical work that has been done in relation to memory and conceptual metaphors is about orientational metaphors as the main focus, like that done by Meier and his colleagues, as mentioned above. Lakoff and Johnson (1980), in their influential book, Metaphors We Live By, distinguish between structural and orientational metaphors. From their point of view, structural metaphors delineate one concept in the form of another concept (like LOVE IS A JURNEY), whereas the orientational metaphors are used to organize a system of concepts with regard to each other (like GOOD IS UP) (Crawford, 2014). In other words, orientational metaphors are metaphors that mainly organize and conceptualize concepts based on spatial orientation such as up, down, back, forward, far, close, etc. The metaphorical function of these spatial orientations stems from the fact that the human body is spatial, and that the form of its body function is the same as its functions in the external environment. The basis of structural metaphors, on the other hand, is to organize one concept within another. Lakoff and Johnson (1980) believe that most metaphors are propositions of this type. To clarify these metaphors, they use the metaphor of "ARGUMENT IS WAR" to show how we conceptualize "verbal debate" through the experience of war and battle (Lakoff \& Johnson, 1980: 14).

It seems that reaction time tasks have been used more than anything else in the studies regarding metaphors to examine how metaphors are understood and processed in comparison to verbal expressions. While, according to recent theories on conceptual metaphors and their functions in cognitive processes and thinking (Lakoff \& Johnson, 1980), the examination of cognitive functions of metaphors is of uttermost importance. Metaphors have versatile communicative and cognitive functions, and they can provide concise and memorizable, yet clear and comprehensible formats for expressing many concepts and thoughts that are difficult to express in verbal (literal) speech. We need to examine the reaction time in this framework (i.e., in relation to the concepts). As a matter of fact, concepts are the building blocks of cognition, and whenever their essence is questioned, the miscellaneous cognitive functions like attention, reasoning, and memory will be followed. Hence, from one perspective, it can be said that conceptual metaphors are considered as the building blocks of cognition (Crawford, 2014). Accordingly, it seems that metaphors play a critical 
role in one of the most paramount cognitive processes i.e., memory and recalling. The topic of recalling and memory has always been considered in cognitive science research and psychology due to its extraordinary significance. On the other hand, many diverse reaction time tasks have been employed in studies related to memory, particularly recognition of short-term memory from a long time ago. For instance, in recognition tasks such as the recognition task by Sternberg (1966), the participants first memorize a list of words. After a short pause, an item (subject stimulus) is shown to them, and they are asked to give a response to it as soon as possible whether the specified item which they memorized existed or not. The task of Sternberg is basically a short-term recognition task in which there is a short pause between the primary list and subject stimulus (Lopes \& Garcia, 2014). Recognition task (new/old) is another type that implements the reaction time test. In this task, participants should decide whether they have recently seen a specific stimulus, or it is new to them. Their reaction time from the moment of seeing the stimulus to the moment of giving an answer is measured in the meantime (Radvansky, 2006).

Based on what was said about the significance of metaphors and their effects on cognition, the present research aims to study the impact of conceptual metaphors of the structural kind on memory: one of the most crucial cognitive processes. To do so, the reaction time task will be applied. Furthermore, in most of the previous research, the perception and processing of metaphors at the level of terms or ultimately a sentence has been compared with the perception and processing of non-metaphors, whereas in this study, the cognitive functions of conceptual metaphors (structural ones) will be scrutinized in the textual context, and will be compared with their corresponding non-metaphorical texts.

\section{Method}

The present study examines the subjects' reaction time in the selection of words belonging to the metaphorical and nonmetaphorical texts. This is a comparative study for the purpose of exploring the relationship between the independent variable (i.e., the number of stimuli that the subjects memorized), and the dependent variable (i.e., reaction time). The matter which should be pointed out regarding stimuli is that there are two groups of words. One is related to schema that has not been mentioned directly in the text, while the other are words that have been applied directly to the texts.

\subsection{Participants}

The statistical sampling of this research has been done in an available randomized sampling manner encompassing students from the age of 20 to 25 at the faculty of foreign languages and the faculty of management of Allameh Tabatabai University, forty of whom were randomly selected. Since the measure of weakness and strength of the memory can be effective on the results of the test, to ascertain the homogeneous relativity of the capability of individuals' memory, the recognition vocabulary test in the Persian language was taken by them (Jarollahi, 2012). For this purpose, the recognition vocabulary test was displayed using PowerPoint for the students. Those students who got the average grade with the standard deviation of \pm 2 were selected for the primary research. Those who scored more or less than the given grade were kept out of the research. Ultimately, the twenty-five students had been elected for the main task, out of which, fifteen were female and ten were male.

\subsection{Stimuli (tasks)}

The main tools of the study were texts which based on the objective of the research had to have multiple fundamental traits. The texts had to be written in fluent Persian language, and they should have been split into two groups of metaphorical and nonmetaphorical. Also, both texts should have a shared schema. Besides, the number of words used in both texts had to be identical. To achieve this purpose meaning the texts with such qualities, the following steps were taken:

A) Writing texts based on available metaphors in Metaphors we live by Lakoff and Johnson (1980). This work has been done upon the validity of linguistic intuition and metaphors function in the Persian language.

B) Writing non-metaphorical texts equivalent to written metaphorical texts. In writing the primary version of the texts, it was attempted to achieve a corresponding number of words and shared schema in both texts.

C) Validation of the metaphorical/non-metaphorical versions by Persian speakers. On that account, the Likert table was prepared with the scores of 1 to 5 and each of them was assigned a score of 100 to 500 . These scores were considered for each text separately. The method of grading was as follows: after the exposition of conceptual metaphor for audiences, they had been asked to give a higher score to the text which they regarded as extremely metaphorical, and whenever it became less metaphorical, it would receive a minor score. To accomplish the desired results which meant grades below 150 for non-metaphorical texts and the grade above 400 for metaphorical texts, this validation had been accomplished in three stages by fifty-eight native speakers of the Persian language. After the completion of every step, the researchers modified the texts according to the achieved results, and again they put it as the touchstone of the test to see the desired results. Ultimately, the texts that didn't obtain proper grades were excluded from the research. The total numbers of three analogous metaphorical texts and three non-metaphorical texts were chosen for the main experiment. 
Afterward, to ascertain the accuracy of the chosen schema by the researchers, the schema of non-metaphorical texts was examined as well. The speakers were asked to choose whatever themes they deemed suitable for each text. Based on the obtained results, the schema of 2 texts out of 3 texts presented to individuals was in accordance with the schema selected by the researchers, and there were differences in one text, which was excluded from the study. For the main task, two filler texts were added to the main texts to eschew systematic error. These texts were non-metaphorical ones that shared no identical schema with the experimented texts.

\subsection{Procedure}

The short-term memory recognition of individuals in relation to a given context was evaluated promptly after the examination to analyze the way an individual accesses a schema upon the metaphorical process. This was also compared with the nonmetaphorical process. After the demonstration of each text, a number of words were shown on display for everyone at tantamount scheduling. The subjects chose that whether they read the term in the context by clicking a button on the keyboard. In the meantime, the reaction time of individuals to each term was registered. To perform the experiment, the research task was designed in Psychopy software. Firstly, the task was examined before in the pilot study in an experimental method to test the method of its function and deal with its shortcomings. Secondly, it was determined to what extent the results of this task are aligned with the objectives of the study. After conducting the pilot study and improving existing faults, and making sure the task was proportional to research objectives, the task was designed in Psychopy software in the visual form. Then, another pilot study was conducted to be certain of how the task works within the software, and its possible defects to be refined. This study was performed in two stages, though the first stage was done to select the subjects and ascertain the relative homogeneity of subjects' capability in memorizing the texts.

The main stage of this research, which was performed a couple of days after the selection of individuals in the selection stage, was the experiment to examine the reaction time of individuals upon the selection of words that automatically appeared on the screen after their exposure to short metaphorical and non-metaphorical texts. This stage was completed through previous arrangements at the Foreign Languages and literature School of Allameh Tabatabai University in the presence of the researcher and each of the subjects individually. Distractions such as loud sounds, unnecessary traffic, and the presence of other people in the room were prevented where possible. The task was operated on an R542UR Asus VivoBook laptop with features like a 15.5-inch aspect ratio, Full HD, and 1920x 1080-pixel resolution. In addition, the distance of subjects to screen display was 40 centimeters. This distance could be altered in compliance with the needs of subjects in terms of being more or less. The texts and words with demonstrated on the screen on a white background, using B Roya Persian font of size 28.

Before performing the test, the researcher ensured subjects that no personal information would be treated as data, and what was important was the total score without considering individual scores. Then, the method and stages of the work were fully explained for them. The test started when the subjects declared to be ready and pushed a button on their keyboard. First, a text was presented on the screen for 25 seconds (in the previous studies, this time was dependent on the length of the text and the study goal. In this study, this duration was determined in a pilot test). After that, a blank white page appeared for 10 seconds, and then the words autonomously and individually would appear on the screen for 4 seconds. The subject selected whichever word he or she thought was used in the text by clicking one of the keyboard buttons. These words were divided into three groups. The first group was the words used directly in the texts, the second group of the words belonged to the non-metaphorical schema of the text, and the third one was the words that had no relationship with the displayed text and were left out in the final analysis. These words were placed together randomly and each displayed individually. After the end of the words' display, a message would appear on the screen page requesting the subject to start the next task by clicking a button. Then, the subject came after the next text.

The texts consisted of 6 texts, two of which were metaphorical and another two were corresponding non-metaphorical and the rest was used as filler. The arrangement of texts' placement was in a form that in one time only, metaphorical text positioned in its place before its opposite version (non-metaphorical). The filler texts, which were associated with terms that were disconnected from displayed texts, were put aside upon data analysis.

\subsection{Data Analysis}

In this study, descriptive and inferential statistical methods were used for analyzing the data and providing tentative answers to the research question. All the analyses were implemented SPSS V.23 software. To compare the reaction time of words in metaphorical and non-metaphorical texts, the paired samples test was used. 


\begin{tabular}{|c|c|c|c|c|c|c|}
\hline \multicolumn{2}{|l|}{ Methods } & Mean & Standard & t-Value & $\begin{array}{l}\text { Degree of } \\
\text { freedom }\end{array}$ & P-Value \\
\hline \multirow[t]{2}{*}{$\begin{array}{l}\text { Pair } \\
1 \text { (metaphorical) }\end{array}$} & $\begin{array}{l}\text { A.1 (schematic } \\
\text { words) }\end{array}$ & $0 / 343$ & $0 / 418$ & \multirow[b]{2}{*}{$-3 / 734$} & \multirow[b]{2}{*}{24} & \multirow[b]{2}{*}{$0 / 001^{(\star \star}$} \\
\hline & $\begin{array}{l}\text { A.2 } \\
\text { (schematic } \\
\text { words) }\end{array}$ & $0 / 655$ & $0 / 336$ & & & \\
\hline \multirow[t]{2}{*}{$\begin{array}{l}\text { Pair } 2 \text { (non- } \\
\text { metaphorical) }\end{array}$} & $\begin{array}{l}\text { A.3 (schematic } \\
\text { words) }\end{array}$ & 0/056 & $0 / 134$ & \multirow{2}{*}{$-3 / 561$} & \multirow{2}{*}{24} & \multirow{2}{*}{$0 / 002^{(* \star}$} \\
\hline & $\begin{array}{l}\text { A.4 (schematic } \\
\text { words) }\end{array}$ & $0 / 237$ & $0 / 253$ & & & \\
\hline \multirow[t]{2}{*}{$\begin{array}{ll}\text { Pair } & 3 \\
\text { (metaphorical) }\end{array}$} & $\begin{array}{l}\text { B.1 (used words } \\
\text { in texts) }\end{array}$ & $1 / 066$ & $0 / 291$ & \multirow{2}{*}{$-1 / 996$} & \multirow{2}{*}{24} & \multirow{2}{*}{$0 / 049^{(*)}$} \\
\hline & $\begin{array}{l}\text { B.2 (used words } \\
\text { in texts) }\end{array}$ & $1 / 221$ & $0 / 381$ & & & \\
\hline \multirow[t]{2}{*}{$\begin{array}{l}\text { Pair } 4 \text { (non- } \\
\text { metaphorical) }\end{array}$} & $\begin{array}{l}\text { B.3 (used words } \\
\text { in texts) }\end{array}$ & $1 / 299$ & $0 / 451$ & \multirow{2}{*}{$1 / 016$} & \multirow{2}{*}{24} & \multirow{2}{*}{$0 / 320$} \\
\hline & $\begin{array}{l}\text { B.4 (used words } \\
\text { in texts) }\end{array}$ & $1 / 387$ & $0 / 329$ & & & \\
\hline
\end{tabular}

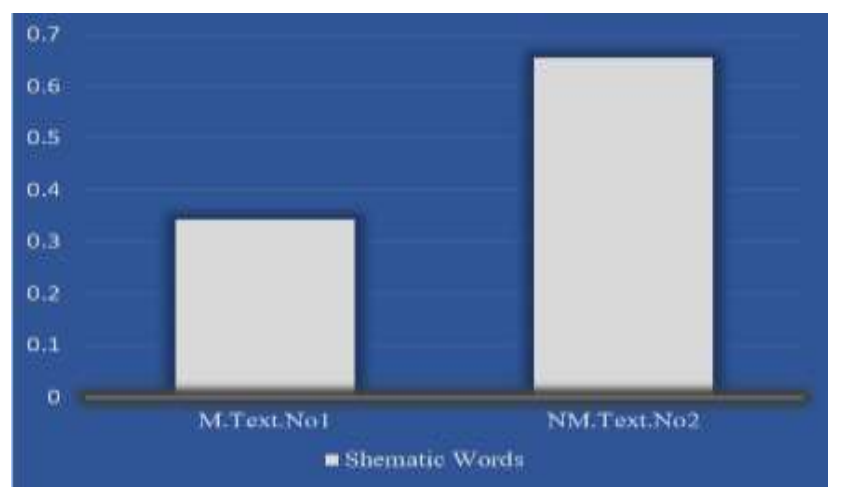

Figure.1: Comparison of schematic words reaction time in metaphorical text No.1 and non-metaphorical text No.2

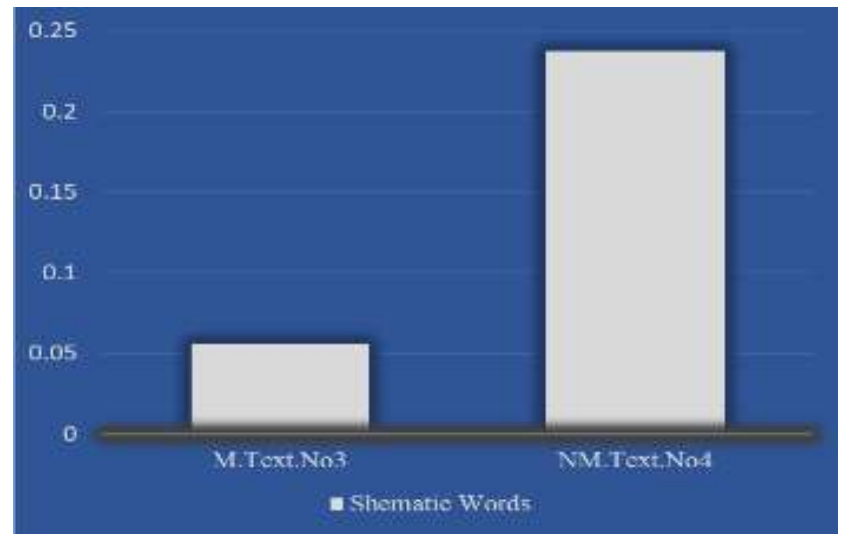

Figure.2: Comparison of schematic words reaction time in metaphorical text No.3 and non-metaphorical text No.4

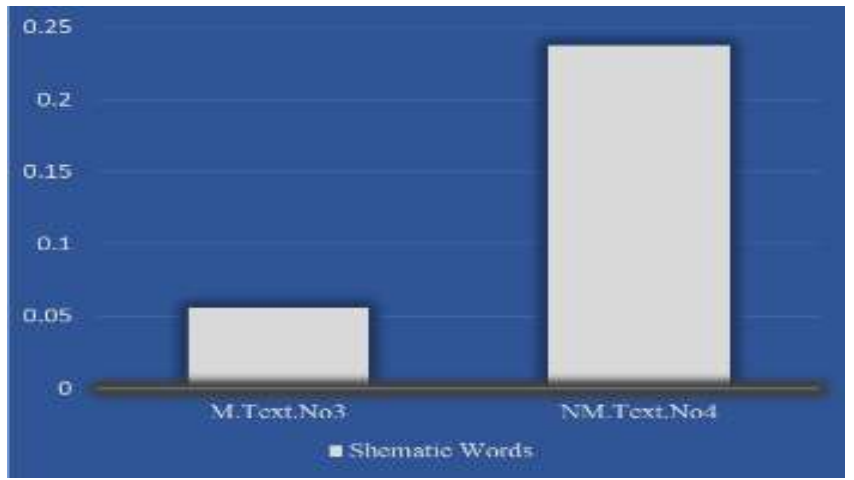

Figure.2: Comparison of schematic words reaction time in metaphorical text No.3 and non-metaphorical text No.4

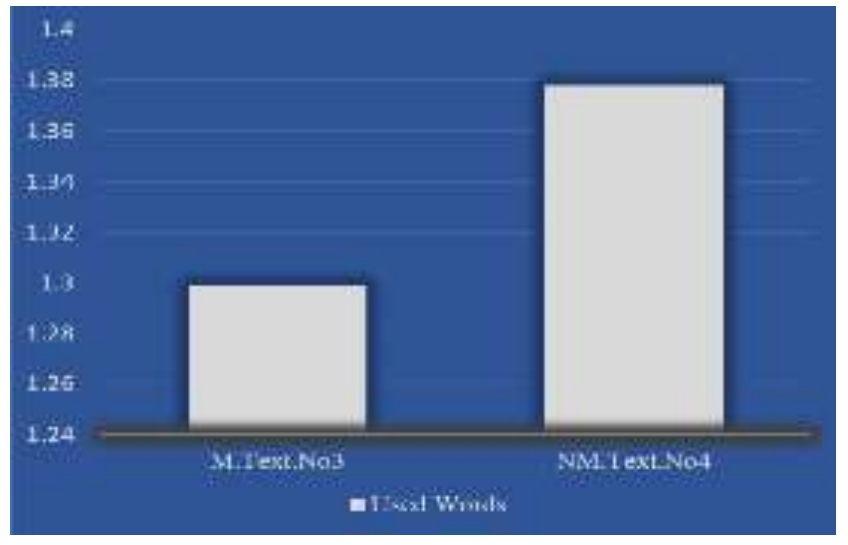

Figure.4: Comparison of used words` reaction time in metaphorical text No.3 and non-metaphorical text No.4 


\section{Discussion}

Lakoff and Johnson (1980) changed the way abstract expressions were understood by proposing and introducing the idea of conceptual metaphors. From their point of view, metaphorical expressions are, in fact, the manifestation of the conceptual mechanisms of the substructure of the mind called conceptual metaphors, which are considered a tool for thinking. For instance, the metaphorical expression "our ideology was assaulted at the session" is the surface manifestation of the substructure of conceptual metaphor [ARGUMENT IS WAR] and will be realized by conceptual mappings in the areas of discussion between war and argument. When one metaphorical expression is used, a conceptual mapping can be achieved, so we can utter a statement or think about an abstract notion like an argument by making use of war which is a palpable and concrete concept.

In this study, we employed two groups of words to make an analogy. One group was directly used in texts while another group was related to the schema of non-metaphorical texts which is supposed to be the substructure of metaphorical texts' schema as well. The results demonstrated that in comparison with metaphorical and their corresponding non-metaphorical texts, the individuals needed less time to recognize the words related to the schema and the words used in the metaphorical texts. First, this finding was exactly in accordance and in line with the research related to the schema which indicates that information in memory is stored as a semantic network of knowledge and therefore, upon recalling one of the segments of the semantic network, other components will be active and individuals might remember things that they had not seen or tried in the recent experience (for further studies check out Bartlett, 1932; Neisser, 1986). One of the main ways of approaching and explaining how concepts and information are related and organized within mind and memory is through schema (Sternberg, 2016). Schema or mental schema is one of the most important conceptual and theoretical structures in the recognition models. The theory of schema describes how the information and knowledge specific to it will be obtained, organized, and processed. The initial speculation of this theory refers to the fact that every perceptual action includes the knowledge of the individual on the world and about the world. Based on this theory, knowledge is the network of cognitive constructs or mental templates. These constructs or templates are called schemata. Actually, schemata organize information saved in long-term memory (Arbib, Conklin \& Hill, 1987), and during the short-term, recalling of information will assist memory. In other words, it can be said that the schemata are higher cognitive constructs that are regarded as the infrastructure of many aspects of humans' knowledge and skill. They also play an important role in the establishment of interaction between old and new knowledge in perceptual processes, thinking, and memory (Brewer \& Nakamura, 1984). Secondly and more importantly for the present study, the subjects recognized terms that belonged to metaphorical texts either related to the schema or the words used in the text faster than the terms in relation to non-metaphorical texts. These terms were either related to the schema or belonged to the texts. With what we know about memory which was mentioned briefly, this point that the memory can be under the influence of metaphorical content is predictable. As mentioned, memory is reconstructive i.e., when individuals are diligently trying to recall past memories, they do not merely go back through time and do not play the precedent incidents and information. Instead, their minds piece together various information and knowledge, regardless of their traces of experience, prior knowledge, and the information registered after the incident, they will remember the experience or concept under-recovery (Loftus, Feldman, \& Dashiell, 1995; Shacter, Guerin, \& St. Jacques, 2011). On the other hand, according to the ever-increasing evidence that some concepts are understood metaphorically, it can be said that metaphors and information related to them are the constituents of reconstructive memory. If that is the case, it is expected that metaphors affect how data is encrypted in memory and their recovery. In fact, if metaphors from the cognitive perspectives are as ubiquitous as what most of the theorists claim (Gibbs, 2006; Lakoff \& Johnson, 1980), they should affect off-line cognition without the presence of the stimulus (in contrast to online cognition with the stimulus) (Crawford, 2014). On-line cognition deals with live tasks that require fast moment-by-moment processing while we switch to slower, off-line cognition when we need to check on something odd or plan future behavior or we need to look at some things that happened in the past.

The findings of this study prove this theory. When subjects read metaphorical texts and then were asked to choose the words they were provided with and were asked to check the ones they thought they saw in the texts, it was observed that metaphors made the access to mind and memory simpler, and they paved the way for individuals to have faster access to the desired elements in comparison with their corresponding non-metaphorical texts. In fact, where cognition without the presence of a stimulus was needed, that is, in the process of recognition, metaphors came to the aid of cognition, i.e., memory, and facilitated mental access to the stimulus. Moreover, the results indicate that the subjects have recognized the words in metaphorical texts related to the schema faster than the same non-metaphorical texts. This finding can be very interesting. Consider the metaphor [ARGUMENT IS WAR] and its non-metaphorical version, and also the texts related to them: Metaphorical text: "Children were still teasing their nurse. Suddenly, the nurse shouted that she would not bear their bad behavior anymore and threatened to confront them if they had not obeyed her. They knew that the nurse's remarks were the declaration of war, but they did not give in despite the possible unfavorable consequences". Non-metaphorical text: "While approaching the enemy's infantry, they were worried about walking on mines and being spotted by the enemy before being able to do anything. Also, the probability of getting farther from the supporting forces intensified their fear. So, they did not have much hope, but they did not withdraw despite the unfavorable consequences". When the text directly refers to the infantry, troops, battle, and the enemies in a concrete and palpable way, it is expected that the access to the schema words related to 'war' will take place and get recognized sooner than the cases they are not the subject of the 
discussion directly and through available mappings existed between the source domain (in this metaphor: war) and the target domain (in this metaphor: argument) the concepts related to the schema of war will be comprehended. It is interesting that in the metaphorical text, we are confronted only with the threatening conversation of the nurse and the children, which has nothing to do with the real battlefield. There is no indication of elements such as soldier, enemy, fire, and smoke. But when subjects were asked to recognize the words that they thought they had seen in the text, and for example, when they saw the word "gun", not only they choose it as the words that they had read in the text but also, they did it faster than the time when the words corresponded to the non-metaphorical text which were really about war and battlefield.

\section{Conclusion}

The results indicated that the terms pertaining to the schema and other terms included in metaphorical context processed faster than the ones with non-metaphorical context. With regard to the obtained data, it seems that the conceptual metaphor generates semantic networks in the mind which will be more accessible to memory upon information retrieval.

Metaphors affect our off-line cognition more than it is mostly thought, and their influence on cognition is not limited to the orientational metaphors and the direct presence of the stimuli as sometimes are mentioned in the literature. This study shows how metaphors are in connection with the various epistemological structures such as schema whose impact on recollection is acknowledged. In addition, this study reveals that as orientational metaphors can influence our online cognition, structural metaphors have the potential to affect our off-line cognition as well.

In general, The findings of this research demonstrate that the study of metaphors' effect on memory can increase our knowledge regarding how metaphors can mold and influence our cognition.

One of the limitations of this study was the small number of subjects studied. By studying more subjects, more relevant and convincing results may be obtained. Furthermore, studying and considering the familiarity of metaphors (i.e., their novelty and conventionality) as well as vividness can affect the results of the study. It is recommended that future researchers consider these points and conduct the experiment.

Funding: This research received no external funding.

Conflicts of Interest: The authors declare no conflict of interest.

ORCID iD

Fatemeh Shafiei: https://orcid.org/0000-0003-4730-125X

Habibollah Ghassemzadeh: https://orcid.org/0000-0003-4180-1093

\section{References}

[1] Allbritton, D. W. (1995). When metaphors function as schemas: Some cognitive effects of conceptual metaphors. Metaphor and Symbolic Activity. 10.1: 33-46.

[2] Arbib, M., Conklin, E. \& Hill, J. (1987). From Schema Theory to Language. New York: Oxford University Press.

[3] Benedek, M., et al. (2014). Intelligence, creativity, and cognitive control: The common and differential involvement of executive functions in intelligence and creativity. Intelligence, 46(1), 73-83.

[4] Bartlett, F. C. (1932). Remembering: A study in experimental and social psychology. Cambridge University Press.

[5] Brewer, W. F., \& Nakamura, G. V. (1984). The nature and functions of schemas. Technical report. No. 325. The University of Illinois at Urbana-Champaign.

[6] Crawford, L. E. (2014). The role of conceptual metaphor in memory. In M. Landau, M. D. Robinson, \& B. P. Meier (Eds.), The power of metaphor: Examining its influence on social life (65-83). American Psychological Association.

[7] Ghassemzadeh, H. (2020). An Introduction to the Cognitive Science of Metaphor. Tehran. Arjmand pub. [In Persian].

[8] Grice, H. P. (1991). Studies in the way of words. Cambridge, MA: Cambridge University Press.

[9] Gibbs, R. W. (2006). Embodiment and cognitive science. Cambridge: Cambridge University Press.

[10] Glucksberg, S. (2001). Understanding figurative language: From metaphors to idioms. Oxford University Press.

[11] Glucksberg, S. (2003). The Psycholinguistics of metaphor. Trends in Cognitive Sciences, 7(2), 92-96.

[12] Jarolahi, F., Delphi, M., Tahaie, S., \& et.al. (2012). Selection of preeminent list in word recognition score test for an adult with normal hearing. Research in Rehabilitation Sciences. 8 (2): 212-218. [In Persian].

[13] Kövecses, Z. (2010). Metaphor: A practical introduction. New York: Oxford University Press.

[14] Lakoff, G., \& Johnson, M. (1980). Metaphors we live by. Chicago: University of Chicago Press.

[15] Loftus, E. F., Feldman, J., \& Dashiell, R. (1995). The reality of illusory memories. In D. L. Schacter (Ed.), Memory distortions: How minds, brains, and societies reconstruct the past (47-68). Harvard University Press.

[16] Lopes, E. J., \& Garcia, R. B. (2014). On the possibility of using reaction time to study false memories. Psychology \& Neuroscience, 7, 3: 393-397.

[17] Meier, B. P., \& Robinson, M. D. (2004). Why the Sunny Side Is Up: Associations Between Effect and Vertical Position. Psychological Science, 15: 243-247.

[18] Meier, B. P., \& Robinson, M. D. (2005). The Metaphorical Representation of effect. Metaphor and Symbol, 20(4), $239-257$.

[19] Meier, B. P., Sellbom, M., \& Wygant, D. B. (2007). Failing to take the moral high ground: Psychopathy and the vertical representation of morality. Personality and Individual Differences, 43: 757-767.

[20] Neisser, U. (1986). Remembering Pearl Harbor: Reply to Thompson and Cowan. Cognition. Vol. 23, No. 3, 285-286. 
[21] Ortony, A. (1978). Metaphor: Theoretical and empirical research. Psychological Bulletin, 85, 919-943.

[22] Posner, M. I. (1978). Chronometric explorations of mind. Hillsadle: Lawrence Erlbaum.

[23] Radvanskey, G. A. (2006). Human memory. Boston: Pearson.

[24] Schacter D. L., Guerin S. A., \& St. Jacques P. L. (2011). Memory distortion: An adaptive perspective. Trends Cogn. Sci, 15: 467-474.

[25] Searle, J. R. (1979). Metaphor. In A. Ortony (Ed.). Metaphor and thought. Cambridge, MA: Cambridge University Press.

[26] Sternberg, R. J., \& Sternberg, K. (2016). Cognitive Psychology. Wadsworth Publishing.

[27] Theio, J. (1973). Reaction time measurements in the study of memory processes: Theory and data. Psychology of Learning and Motivation, 7. 43-85.

[28] Welford, A. T. (1980). Reaction times. New York: Academic Press.

\section{Appendix}

Text 1: Metaphorical: "THEORY IS BUILDING"

A group of researchers was searching for a strong foundation for a theory because some of the opponents of that theory had claimed that the reasoning basis for the theory is weak and it is will be disproved. These researchers wanted to support that theory by providing strong reasoning basis and presenting its frameworks fundamentally.

Text 3: Metaphorical: "ARGUMENT IS WAR"

Children were still annoying their nurse. Suddenly, the nurse shouted that she will not bear their bad behavior and threatened them with punishment if they did not obey her. They knew that the nurse's remarks were a declaration of war, but they did not give in despite the unfavorable consequences.
Text 2: Non-Metaphorical

A group of engineers wanted to see the materials used in a tower because some experts had claimed that the foundations of the tower are weak and would be destroyed. These engineers wanted to ensure the strength of that tower by providing high-quality materials and fundamentally consolidating its framework.

\section{Text 4: Non-Metaphorical}

While approaching the enemy's infantry, they were worried about encountering mines and being spotted by the enemy before being able to do anything. Also, the probability of getting far from the supporting forces intensified their fear. So, they did not have much hope, but they did not withdraw despite the unfavorable consequences. 